\title{
Will the Conversion from Sanatorium Medical Facilities into New Facilities Progress in Japan?
}

\author{
Yuka Mine ${ }^{1}$, Masayuki Yokoi ${ }^{2} \&$ Takao Tashiro $^{1}$ \\ ${ }^{1}$ Graduate School of Open University of Japan, Chiba, Japan \\ ${ }^{2}$ Pascal Pharmacy, Shiga, Japan \\ Correspondence: Yuka Mine, The Open University of Japan, 2-11 Wakaba, Mihama-ku, Chiba City, 261-8586. \\ Tel: 81-70-5682-6138. E-mail: mura@m3.gyao.ne.jp
}

Received: June 13, 2020 Accepted: July 10, 2020 Online Published: July 14, 2020

doi:10.5539/gjhs.v12n10p7 URL: https://doi.org/10.5539/gjhs.v12n10p7

\begin{abstract}
In Japan, under the Long-Term Care Insurance Act of 2018, the Integrated Facility for Medical and Long-Term Care was established as a new long-term care insurance facility into which Sanatorium Medical Facilities could be converted, and this conversion has taken place gradually; in this study, we compared the management policies between existing Sanatorium Medical Facilities and Integrated Facilities. We also examined the management policies of Geriatric Health Services Facilities. For the management policies of individual facilities, published data on the "Long-Term Care Service Information Publication System" website were used; the study included 142 Integrated Facilities, 245 Sanatorium Medical Facilities, and 237 Geriatric Health Services Facilities. The percentage of facilities in each facility group that included specific keywords was compared. There were no significant differences in the percentage of facilities including "Return," "Long-term," "Management," "Care," and "Coordination" in their management policies between Sanatorium Medical Facilities and Integrated Facilities. Compared with Geriatric Health Services Facilities, Sanatorium Medical Facilities had a significantly lower rate of including "Return" and a significantly higher rate of including "Long-term," "Management," "Care," and "Coordination." As seen from the above, the management policies of Sanatorium Medical Facilities were similar to those of Integrated Facilities, rather than Geriatric Health Services Facilities. When Geriatric Health Services Facilities and Integrated Facilities were compared as candidates for conversion from Sanatorium Medical Facilities, it was suggested that the barrier to entry is lower for the Integrated Facilities than for Geriatric Health Services Facilities in terms of necessity of major change in management policies.
\end{abstract}

Keywords: facility, geriatric medicine, hospital, Japan, long-term care, terminal care

\section{Introduction}

Long-term care beds in Japan are defined under the Medical Care Act as beds primarily for hospitalization of patients requiring long-term care, and they have been operated separately as beds covered by medical insurance and beds covered by long-term care insurance (hereafter referred to as "Sanatorium Medical Facilities") since the Long-Term Care Insurance Act came into effect in 2000 (Ministry of Health, Labour and Welfare [MHLW], 2008b; MHLW, 2002). With the population expected to age rapidly, Sanatorium Medical Facilities were decided to be abolished in 2012, and existing Sanatorium Medical Facilities were to be converted into one of long-term care insurance services by 2012 (MHLW, 2008a).

The government provided various support measures on personnel and facility standards so that existing Sanatorium Medical Facilities could be converted smoothly into "Geriatric Health Services Facilities." This was because Geriatric Health Services Facilities were numerically closest to existing Sanatorium Medical Facilities in terms of medical staffing standards and facility standards among the various long-term care insurance services existing at that time (MHLW, 2008c; MHLW, 2011). However, conversion into Geriatric Health Services Facilities did not progress. Although the actual operating deadline for Sanatorium Medical Facilities was extended for another six years from 2012, their conversion still did not progress, and this period was extended again for another six years from 2018 (MHLW, 2017; MHLW, 2018).

It is recognized that the transition from Sanatorium Medical Facilities into Geriatric Health Services Facilities did not occur sufficiently because the official price for facility standards and personnel standards for Geriatric 
Health Services Facilities was not profitable enough to encourage Sanatorium Medical Facilities to be converted into one of them. This was revealed from the results of a government questionnaire survey in Sanatorium Medical Facility owners (MHLW, 2010). In addition to this theory, we compared the "philosophy" of hospitals with a large number of long-term care beds with that of Geriatric Health Services Facilities with many beds, and revealed that existing Sanatorium Medical Facilities and Geriatric Health Services Facilities, in fact, had management philosophies that were fundamentally different. Specifically, Geriatric Health Services Facilities are facilities that invest medical resources in order to enable residents to return home; whereas hospitals with long-term care beds can accept the situation of inpatients even if it may be practically difficult for them to return home and can work systematically toward terminal care, which differentiate hospitals from nearby Geriatric Health Services Facilities. With priority put on the restoring of the nation's fiscal health, the policy to eliminate and convert Sanatorium Medical Facilities into long-term care insurance facilities was inevitably decided; hospitals with long-term care beds may have indicated opposition to the Japanese government which left them with no choice but to convert themselves into facilities that have very different management philosophies (Mine, Yokoi, \& Tashiro., 2019).

Under the Long-Term Care Insurance Act of 2018, in addition to re-extending the operation deadline of Sanatorium Medical Facilities, a new type of long-term care insurance service called the "Integrated Facility for Medical and Long-Term Care" was established. Before the establishment of Integrated Facilities for Medical and Long-Term Care, experts made investigations on future medical and long-term care systems that meet the chronic stage medical needs. As a result, they concluded that it was necessary to establish a new type of facility that ensures function as a "home" but also includes medical care functions. In line with this concept, the Integrated Facility for Medical and Long-Term Care was defined under the Long-Term Care Insurance Act as a facility for elderly persons with long-term medical and nursing care needs which combines medical functions (e.g., "daily medical management," "end-of-life and terminal care") with a function as a "residential facility" (MHLW, 2018).

Since the Integrated Facility for Medical and Long-Term Care was established in 2018, conversion of Sanatorium Medical Facilities into this service type has occurred gradually; however, will more conversions take place in the future? As with our previous study, we see the benefit of specifically comparing the management policies of individual Sanatorium Medical Facilities with those of individual Integrated Facilities for Medical and Long-Term Care to find out whether there is any affinity between them. In this study, the authors extracted management policies of the first facilities that established Integrated Facilities for Medical and Long-Term Care by the end of 2019 and those of existing Sanatorium Medical Facilities and compared the characteristics of the keywords contained in them. As a reference, we also made comparisons with management policies of Geriatric Health Services Facilities, and with management policies of Nursing Care Homes, which are not required to be staffed by full-time doctors.

Of note, Integrated Facilities for Medical and Long-Term Care have been newly established in 2018, and we could not find any literature that quantitatively analyzed their management policies.

\section{Methods}

Based on the Long-Term Care Insurance Act, Japan has the "Publication System of Long-Term Care Service Information," which is a system to provide information that helps users to compare and select appropriate nursing care services, providers, or facilities. Based on this system, basic information of approximately 210000 long-term care service providers throughout Japan is made publicly available by each prefecture on the "Long-Term Care Service Information Publication System" website (MHLW, 2006). Of the facilities provided on the website, the authors selected all Integrated Facilities for Medical and Long-Term Care and randomly selected $25 \%$ of Sanatorium Medical Facilities from each prefecture. Additionally, as a reference, we randomly selected 5\% of Geriatric Health Services Facilities from each prefecture and 2.5\% of Nursing Care Homes from each prefecture. These are the four groups of facilities studied in this study. "Management policy" was a required field for all facility groups, so we extracted text from this field and compared the characteristics of the keywords contained in the text by each type of facility. The date of access to the Long-Term Care Service Information Publication System website was January 1, 2020.

First, we tabulated the number of facilities in each facility group that included specific keywords and compared the rates using the chi-square test. A p-value of 0.05 or less was considered significant. IBM SPSS Statistics 25 was used for this test.

We also performed an interval estimation for the rates of relevant facilities using the formula (1), with a confidence interval of $95 \%(k=1.96)$. 


$$
\hat{p}-k \sqrt{\frac{\hat{p}(1-\hat{p})}{n}}<P<\hat{p}+\sqrt{\frac{\hat{p}(1-\hat{p})}{n}}
$$

The only data used in this study were data provided to each prefecture by the facilities knowing that the information would be made publicly available through the website. Analysis was performed without linking these data to information unique to each facility. Therefore, this study has not gone through the process of obtaining individual consent from the facilities studied or from each prefecture nor the process to obtain approval from the ethics committee.

\section{Results}

\subsection{Basic Attributes of Surveyed Facilities}

Facilities selected were 142 Integrated Facilities for Medical and Long-Term Care (all facilities listed at the time of investigation) and 245 Sanatorium Medical Facilities (25\% selected). In addition, 237 Geriatric Health Services Facilities (5\% selected) and 222 Nursing Care Homes (2.5\% selected) were selected for reference.

Integrated Facilities for Medical and Long-Term Care included in this study had an average of $60.4 \pm 40.2$ beds. On the other hand, as of December 31, 2019 the Japanese government has identified a total of 301 Integrated Facilities for Medical and Long-Term Care with a total of 18931 beds, an average of 62.9 beds per facility (MHLW, 2020, May 1). Sanatorium Medical Facilities included in this study had an average of $51.6 \pm 62.2$ beds. On the other hand, as of October 1, 2017 the government has identified a total of 1196 Sanatorium Medical Facilities with a total of 53352 beds, an average of 44.6 beds per facility (MHLW, 2018, September 20).

\subsection{Percentage of Including Individual Keywords}

The number and percentage of facilities that include specific keywords in their management policy are shown by facility group in Table 1 .

Table 1. Number and percentage of facilities including specific keywords in their management policy

\begin{tabular}{lcccc}
\hline $\begin{array}{c}\text { Facility } \\
\text { (Number of } \\
\text { facilities) }\end{array}$ & $\begin{array}{c}\text { Integrated Facility } \\
\mathbf{( 1 4 2 )}\end{array}$ & $\begin{array}{c}\text { Sanatorium Medical } \\
\text { Facility } \\
\mathbf{( 2 4 5 )}\end{array}$ & $\begin{array}{c}\text { Health Services } \\
\text { Facility } \\
\mathbf{( 2 3 7 )}\end{array}$ & $\begin{array}{c}\text { Nursing Care Home } \\
\mathbf{( 2 2 2})\end{array}$ \\
\hline "Return" & $19(13 \%)$ & $20(8 \%)$ & $141(59 \%)$ & $56(25 \%)$ \\
"Long-term" & $58(41 \%)$ & $112(46 \%)$ & $0(0 \%)$ & $0(0 \%)$ \\
"Management" & $90(63 \%)$ & $162(66 \%)$ & $96(41 \%)$ & $35(16 \%)$ \\
"Care" & $76(54 \%)$ & $123(50 \%)$ & $73(31 \%)$ & $37(17 \%)$ \\
"Coordination" & $66(46 \%)$ & $112(46 \%)$ & $67(28 \%)$ & $42(19 \%)$ \\
"Independence" & $83(58 \%)$ & $144(59 \%)$ & $136(57 \%)$ & $89(40 \%)$ \\
"Community" & $79(56 \%)$ & $99(40 \%)$ & $111(47 \%)$ & $101(45 \%)$ \\
\hline
\end{tabular}

Although there were no significant differences in the percentage of facilities including "Return," "Long-term," "Management," "Care," and "Coordination" between Sanatorium Medical Facilities and Integrated Facilities for Medical and Long-Term Care (Return: $p=0.100$, Long-term: $p=0.352$, Management: $p=0.585$, Care: $p=0.529$, Coordination: $p=0.884$ ), significant differences were observed for all keywords between Sanatorium Medical Facilities and Geriatric Health Services Facilities. Compared with Geriatric Health Services Facilities, Sanatorium Medical Facilities had a significantly lower rate of including "Return" $(p=0.000)$ and a significantly higher rate of including "Long-term," "Management," "Care," and "Coordination" (Long-term: $p=0.000$, Management: $p=0.000$, Care: $p=0.000$, Coordination: $p=0.000$ ).

No significant difference in the percentage of facilities including "Independence" was found between Sanatorium Medical Facilities and Integrated Facilities for Medical and Long-Term Care $(p=0.950)$ or between Sanatorium Medical Facilities and Geriatric Health Services Facilities $(p=0.757)$.

The percentage of facilities including "Community" was significantly lower in Sanatorium Medical Facilities than in Integrated Facilities for Medical and Long-Term Care $(p=0.004)$. It was also lower compared to Geriatric Health Services Facilities, but the difference was not statistically significant $(p=0.155)$. 
The percentage of facilities including specific keywords in their management policy and their $95 \%$ confidence intervals are shown by facility group in Table 2 .

Table 2. Percentage of facilities including specific keywords in their management policy

\begin{tabular}{|c|c|c|c|c|}
\hline \multirow{2}{*}{ Keywords } & & \multirow{2}{*}{$M$} & \multicolumn{2}{|c|}{$95 \% \mathrm{CI}$} \\
\hline & & & $\mathbf{L L}$ & $\mathbf{U L}$ \\
\hline \multirow{4}{*}{ "Return" } & Integrated Facility & 0.13 & 0.07 & 0.19 \\
\hline & Sanatorium Medical Facility & 0.08 & 0.05 & 0.11 \\
\hline & Health Services Facility & 0.59 & 0.53 & 0.65 \\
\hline & Nursing Care Home & 0.25 & 0.19 & 0.31 \\
\hline \multirow{4}{*}{ "Long-term" } & Integrated Facility & 0.41 & 0.33 & 0.49 \\
\hline & Sanatorium Medical Facility & 0.46 & 0.40 & 0.52 \\
\hline & Health Services Facility & 0.00 & 0.00 & 0.00 \\
\hline & Nursing Care Home & 0.00 & 0.00 & 0.00 \\
\hline \multirow{4}{*}{ "Management" } & Integrated Facility & 0.63 & 0.55 & 0.71 \\
\hline & Sanatorium Medical Facility & 0.66 & 0.60 & 0.72 \\
\hline & Health Services Facility & 0.41 & 0.35 & 0.47 \\
\hline & Nursing Care Home & 0.16 & 0.11 & 0.21 \\
\hline \multirow{4}{*}{ "Care" } & Integrated Facility & 0.54 & 0.46 & 0.62 \\
\hline & Sanatorium Medical Facility & 0.50 & 0.44 & 0.56 \\
\hline & Health Services Facility & 0.31 & 0.25 & 0.37 \\
\hline & Nursing Care Home & 0.17 & 0.12 & 0.22 \\
\hline \multirow{4}{*}{ "Coordination" } & Integrated Facility & 0.46 & 0.38 & 0.54 \\
\hline & Sanatorium Medical Facility & 0.46 & 0.40 & 0.52 \\
\hline & Health Services Facility & 0.28 & 0.22 & 0.34 \\
\hline & Nursing Care Home & 0.19 & 0.14 & 0.24 \\
\hline \multirow{4}{*}{ "Independence" } & Integrated Facility & 0.58 & 0.50 & 0.66 \\
\hline & Sanatorium Medical Facility & 0.59 & 0.53 & 0.65 \\
\hline & Health Services Facility & 0.57 & 0.51 & 0.63 \\
\hline & Nursing Care Home & 0.40 & 0.34 & 0.46 \\
\hline \multirow{4}{*}{ "Community" } & Integrated Facility & 0.56 & 0.48 & 0.64 \\
\hline & Sanatorium Medical Facility & 0.40 & 0.34 & 0.46 \\
\hline & Health Services Facility & 0.47 & 0.41 & 0.53 \\
\hline & Nursing Care Home & 0.45 & 0.38 & 0.51 \\
\hline
\end{tabular}

Note. $\mathrm{CI}=$ confidence interval; $\mathrm{LL}=$ lower limit, $\mathrm{UL}=$ upper limit.

As regards the percentage of facilities including "Return," "Long-term," "Management," "Care," and "Coordination," an overlap of the 95\% confidence intervals was observed between Sanatorium Medical Facilities and Integrated Facilities for Medical and Long-Term Care, but no overlap in the $95 \%$ confidence intervals was observed between Sanatorium Medical Facilities and Geriatric Health Services Facilities.

For the percentage of facilities that include "Independence," an overlap of the $95 \%$ confidence intervals was observed between Sanatorium Medical Facilities and Integrated Facilities for Medical and Long-Term Care and between Sanatorium Medical Facilities and Geriatric Health Services Facilities. 
Regarding the percentage of facilities including "Community," there was no overlap of the $95 \%$ confidence intervals between Sanatorium Medical Facilities and Integrated Facilities for Medical and Long-Term Care, but an overlap in 95\% confidence intervals between Sanatorium Medical Facilities and Geriatric Health Services Facilities was observed.

\section{Discussion}

In this study, the authors intentionally selected several keywords that were considered symbolic in comparing the types of facilities. Therefore, the study could not systematically investigate every keyword. In addition, because we placed priority on obtaining the same numbers of Geriatric Health Services Facilities and Nursing Care Homes as Integrated Facilities for Medical and Long-Term Care or Sanatorium Medical Facilities within limited efforts, the sampling rate was as low as $5 \%$ and whether they are representative of the parent population is inadequately verified.

In spite of such limitations, when Sanatorium Medical Facilities and Integrated Facilities for Medical and Long-Term Care were compared, Integrated Facilities for Medical and Long-Term Care had a significantly higher rate of including "Community" in their management policy. However, other than "Community," there were no significant differences in any keywords explored by the authors (including those omitted from this paper) between Sanatorium Medical Facilities and Integrated Facilities for Medical and Long-Term Care.

On the other hand, when Sanatorium Medical Facilities and Geriatric Health Services Facilities were compared, significant differences were observed for many keywords, such as "Return," "Long-term," "Management," "Care," and "Coordination."

According to the Long-Term Care Insurance Act, Sanatorium Medical Facilities (which have been decided to be abolished) are facilities that provide medical care and nursing care under medical management for long-term patients. In contrast, Geriatric Health Services Facilities, to which Sanatorium Medical Facilities were to be converted initially by 2012, are facilities that provide rehabilitation and other services aimed at returning home (Japanese Law Translation Database System, 2009). On the other hand, Integrated Facilities for Medical and Long-Term Care, which have been newly established in 2018 as major candidates for Sanatorium Medical Facilities to be converted into, are defined as facilities that provide medical care and nursing care for daily activities in an integrated fashion (MHLW, 2018a). In other words, according to the concept of the Long-Term Care Insurance Act, Integrated Facilities for Medical and Long-Term Care basically take on the role of Sanatorium Medical Facilities, with an added function as a place for living everyday life.

In fact, this concept of Integrated Facilities for Medical and Long-Term Care was examined and created so that conversions would progress this time, in consideration of the past failure to have Sanatorium Medical Facilities converted into Geriatric Health Services Facilities. Therefore, we could naturally expect before research that Integrated Facilities for Medical and Long-Term Care, rather than Geriatric Health Services Facilities, had higher affinity with Sanatorium Medical Facilities in terms of management policy after conversion. Also, in this study, we did not make direct comparisons by following the changes in the management policies of the same facility before and after conversion from a Sanatorium Medical Facility.

However, this was the first study to demonstrate that, based on the population attributes of management policies of existing types of facilities, the management policies of Sanatorium Medical Facilities were similar to those of Integrated Facilities for Medical and Long-Term Care that have been established, rather than Geriatric Health Services Facilities.

Although it has been decided that Sanatorium Medical Facilities will be abolished by 2024, some Sanatorium Medical Facilities remain undecided on which facility to be converted into. This study has a certain significance in that, when Geriatric Health Services Facilities and Integrated Facilities for Medical and Long-Term Care were compared as candidates for conversion, it suggested that the barrier to entry is lower for the newly established Integrated Facilities for Medical and Long-Term Care than for Geriatric Health Services Facilities in terms of necessity of major change in management policies.

Of note, being aware of adding the function to support the users' daily life to their former function as an inpatient facility, a certain number of Integrated Facilities for Medical and Long-Term Care may have naturally included "Community" in their management policies; this may explain why Integrated Facilities for Medical and Long-Term Care had a significantly higher rate of including "Community" compared to Sanatorium Medical Facilities. 


\section{Conclusion}

The Integrated Facility for Medical and Long-Term Care was established in 2018, and since then, Sanatorium Medical Facilities have gradually been converted into this service type; in order to help predict whether more conversions would take place in the future, we extracted the management policies from facilities that established Integrated Facilities for Medical and Long-Term Care by the end of 2019 and from existing Sanatorium Medical Facilities, and we compared the characteristics of the keywords included these management policies. As a reference, we extracted and examined the management policies of Geriatric Health Services Facilities. For the management policies of individual facilities, we used the data published on the "Long-Term Care Service Information Publication System" website as of January 1, 2020.

As a result of comparing Sanatorium Medical Facilities and Integrated Facilities for Medical and Long-Term Care, no significant differences were observed in the inclusion rate for any keywords except for "Community" between Sanatorium Medical Facilities and Integrated Facilities for Medical and Long-Term Care. On the other hand, when Sanatorium Medical Facilities and Geriatric Health Services Facilities were compared, significant differences were observed in the inclusion rate for many keywords, such as "Return," "Long-term," "Management," "Care," and "Coordination."

This was the first study to demonstrate that, based on the population attributes of management policies of existing types of facilities, the management policies of Sanatorium Medical Facilities were similar to those of Integrated Facilities for Medical and Long-Term Care that have been established, rather than Geriatric Health Services Facilities, through keyword analysis.

When Geriatric Health Services Facilities and Integrated Facilities for Medical and Long-Term Care were compared as candidates for conversion from Sanatorium Medical Facilities, it was suggested that the barrier to entry is lower for the Integrated Facilities for Medical and Long-Term Care than for Geriatric Health Services Facilities in terms of necessity of major change in management policies.

\section{Competing Interests Statement}

The authors declare that there are no competing or potential conflicts of interest.

\section{References}

Japanese Law Translation Database System. (2009, April 1). Long-Term Care Insurance Act, law number: Act No.123 of 1997, last version: Amendment of act No.110 of 2007, dictionary ver: 2.0. Retrieved from $\mathrm{http}: / / \mathrm{www}$.japaneselawtranslation.go.jp/law/detail/?id=94\&vm=02\&re=2\&new=1

Mine, Y., Yokoi, M., \& Tashiro, T. (2019). Why Did the Policy to Convert Hospitals Into Facilities Not Work in Japan?, Global Journal of Health Science, 11(10), 89-96. https://doi.org/10.5539/gjhs.v11n10p89

Ministry of Health, Labour and Welfare. (2002, July). The long-term care insurance system. Retrieved from https://www.mhlw.go.jp/english/topics/elderly/care/2.html

Ministry of Health, Labour and Welfare. (2006). The disclosure system of long-term care service providers in Japan. [Japanese] Retrieved from https://www.kaigokensaku.mhlw.go.jp/

Ministry of Health, Labour and Welfare. (2008a). Annual Health, Labour and Welfare Report 2007-2008, part 3 References, health and medical services, p28-p33. Retrieved from https://www.mhlw.go.jp/english/wp/wp-hw2/part2/p3_0001.pdf

Ministry of Health, Labour and Welfare. (2008b). Annual Health, Labour and Welfare Report 2007-2008, part 3 References, health and medical services, 41-43. Retrieved from https://www.mhlw.go.jp/english/wp/wp-hw2/part2/p3_0006.pdf

Ministry of Health, Labour and Welfare. (2008c). Annual Health, Labour and Welfare Report 2007-2008, part 3 References, health and welfare services for the elderly, p228. Retrieved from https://www.mhlw.go.jp/english/wp/wp-hw2/part2/p3_0019.pdf

Ministry of Health, Labour and Welfare. (2010, April 30). Summary of results of the survey on the intention to convert long-term care hospital beds. [Japanese] Retrieved from https://www.mhlw.go.jp/topics/kaigo/hoken/dl/seido02_6.pdf

Ministry of Health, Labour and Welfare. (2011, November 10). Data for the 84th long-term care benefits subcommittee, 4, standards and fee for sanatorium medical facility and medical service facility. [Japanese] Retrieved from https://www.mhlw.go.jp/stf/shingi/2r9852000001uuqn-att/2r9852000001uutw.pdf 
Ministry of Health, Labour and Welfare. (2017). Annual Health, Labour and Welfare Report 2017, References, I. Overview of the system and the basic statistics, 10 health and welfare services for the elderly. Retrieved from https:/www.mhlw.go.jp/english/wp/wp-hw11/d1/10e.pdf

Ministry of Health, Labour and Welfare. (2018a). Outline of the revision of the long-term care insurance system, etc. to strengthen the community-based integrated care system in 2017-18. Retrieved from https://www.mhlw.go.jp/english/policy/care-welfare/care-welfare-elderly/dl/ltcis_2017_e.pdf

Ministry of Health, Labour and Welfare. (2018, September 20). Survey of institutions and establishments for long-term care 2017, Summary of results. [Japanese] Retrieved from https://www.mhlw.go.jp/toukei/saikin/hw/kaigo/service17/dl/kekka-gaiyou.pdf

Ministry of Health, Labour and Welfare. (2020, May 1). About a new type of facility covered by long-term care insurance (integrated facility for medical and long-term care). [Japanese] Retrieved from https://www.mhlw.go.jp/stf/seisakunitsuite/bunya/0000196478.html

\section{Copyrights}

Copyright for this article is retained by the author(s), with first publication rights granted to the journal.

This is an open-access article distributed under the terms and conditions of the Creative Commons Attribution license (http://creativecommons.org/licenses/by/4.0/). 